\title{
VICTIM-BLAMING AND THE CRISIS OF REPRESENTATION IN THE VIOLENCE PREVENTION FIELD
}

\author{
Elizabeth Fast and Cathy Richardson
}

\begin{abstract}
In this article, the authors apply response-based practice to highlight the ways in which victims are blamed in cases of violence. They problematize and explore the misrepresentation of violence across academic disciplines and institutional systems, including the social sciences, the helping professions, and the justice system. Fast and Richardson discuss the linguistic operations that serve to conceal violence and also to obscure the resistance of the victim, which tends to reflect the level and brutality of the violent acts. In order to demonstrate the processes of shifting blame and responsibility from the perpetrator to the victim, the authors also discuss particular Indigenous examples relating to the issue of attacks on and kidnappings of Indigenous women, and to the connections between violence, resource exploitation, and land dispossession.
\end{abstract}

Keywords: victim-blaming, response-based practice, Indigenous, Métis, structural violence

Elizabeth Fast PhD, Métis (corresponding author) is an Assistant Professor in the Department of Applied Human Sciences, Concordia University, Vanier Extension, 7141 Sherbrooke West, Montreal, QC H4B 1R6. Email: Elizabeth.fast@concordia.ca

Cathy Richardson/Kinewesquao $\mathrm{PhD}$ is a Métis Associate Professor in Social Work at the University of Montreal, Pavillon Lionel Groulx, 3150 rue Jean Brillant, Montreal, QC H3T 1N8. Email: Catherine.richardson@ umontreal.ca 
International Journal of Child, Youth and Family Studies (2019) 10(1): 3-25

What is a crisis of representation? It is a conflict over how to represent events in the most accurate manner - a fight for centrality, or for the truth, so to speak. In the fields of violence against women and domestic violence, we see competing representations through ideas and theories that (a) present violence against women/mothers as an issue of misogyny; (b) present violence against female partners as a family or domestic problem; (c) present violence against women as linked to a problem or deficit within women and therefore blame and pathologize women. Our view is practice-informed and based on the idea that all people prefer to be treated with kindness and respect, and that when they are being harmed they try to stop it in some way (Wade,1997). Through private practice and research, we understand that those who perpetrate violence do it with deliberation and it is a "violence issue", not an issue of alcohol use, mental health, anger management, or being "preprogrammed" for violence. As such, this article explores the construct of victim-blaming and the purposes it serves, such as excusing the perpetrator and positioning the perpetrator in positions of power over those ones who have been targeted and harmed.

The term "crisis of representation" was borrowed from a period of transition in the academic world, particularly in the social sciences, that was in full swing by the mid-1980s. The critical focus on the legitimacy of the big social theories was being questioned, as were the ways of knowing and of creating knowledge, and the limits of positivism. What emerged in the mid1990s from this crisis was an engagement with scientific texts, which were ostensibly based on "facts" and "truth", and a broader focus on meaning, discursive representations, and a more reflexive approach to the practice of social sciences (Rudenko, 2017). Throughout history, there have been shifts of understanding, in paradigm, and in the representation of public events.

European history has been coloured by the struggle for religious and political dominance. The Holy Roman Empire overtook pagan lands and imposed its religion. In 325 AD, the Council of Nicea articulated their preferred relationship between humans, deities (God and Jesus), the human soul, and civic holidays, notions that would become doctrinal truths (Whipps, 2008). Later, struggles for dominance continued in Europe with articulations of world and military history varying within the narratives of the conquerors and the conquered. Representations of events differed according to who controlled the dominant narrative, typically those with hegemony (Foucault, 1991; Gramsci, 1971).

More recently, events with police in the Quebec city of Val-d'Or (2016) drew attention to this struggle for representation. Over 37 Indigenous women accused police (members of la Sûreté du Québec) of physical and sexualized abuse (Shingler, 2016). After an investigation by Montreal police, charges were brought against six officers, who denied the accusations; the charges were finally dropped for lack of sufficient evidence to build a conclusive case (Val-d'Or crisis, 2016). Officers initiated a "ribbon campaign", wearing wristbands to show solidarity with fellow accused officers. Édith Cloutier, the executive director of the Val-d'or Friendship Centre, stated that 
International Journal of Child, Youth and Family Studies (2019) 10(1): 3-25

“officers have even showed up at Willie's Place, a drop-in centre for homeless Native people, wearing the bands along with their police uniforms... The police now want to be seen as the victims." (Val-d'Or crisis, 2016). In a joint declaration, 12 of the women accusers stated that they felt "betrayed [and] humiliated" (Val-d'Or crisis, 2016). In such a situation, impunity is achieved for perpetrators, or for those in positions of power, and the victims are blamed for the events and for misrepresenting the truth. They are even named as the perpetrators. There are multiple issues of concern in the area of violence against women and violence against Indigenous people; the struggle for representation is only one of them.

\section{Murdered and Missing Indigenous Women}

In regards to the murdered and missing women in Canada, responsibility for the violence is often ascribed to the vulnerability of Indigenous women as in Amnesty International's Report on the Stolen Sisters (2004). This representation is ubiquitous, but it is an interpretation that presupposes that there is something about being an Indigenous woman - a deficit, or something wrong about them - that accounts for their victimization. If we instead viewed the mix of violence and racism as a social issue, the descriptors of the events would focus on a problem in the social world, highlighting the responsibility of the perpetrator. Instead, the issue is primarily characterized, abstractly, as frightened women. This identifies the problem as a psychological state in the mind of the (potential) victim. This discursive representation feeds into the faulty notions that victims are to blame for the violence and that the problem could be overcome by sending girls and women to classes in self-defence and in fear management, so they can learn how not to appear weak or afraid. This type of victim-blaming analysis is often found in the context of schools in relation to what is called "bullying". The thinking is, "If we toughen up the ones who are getting attacked, the violence will stop." Of course, this approach neglects the responsibility of the perpetrators, and implicitly accords them impunity or power in the system. In pointing out the problem of this logic, Allan Wade has said that we have tried to change the behaviour of violent men, for decades, by tampering with the minds of women and "it hasn't worked" (Wade, personal communication, Duncan, BC, Canada, 2015). Similar language is used in Amnesty International's Report on the Stolen Sisters, as noted by Richardson (2009), speaking on a panel at the United Nations Permanent Forum on Indigenous Peoples.

\section{The Prevalence of Aggressors and Impunity}

Alternatively, and more accurately, instead of framing the issue as a problem of the vulnerability of women, it could be framed as the problem of the high number of men in Canada willing to use violence against women in general or Indigenous women in particular. While courts tend to focus on the actions of the perpetrator, almost all other disciplines focus on the presentation and pathology of the violence against victims: these disciplines include psychology and child protection (Coates \& Wade, 2007; Garkawe, 1992; Richardson \& Wade, 2009; Wade, personal communication, 2014). With this victim-focus, victims are held accountable for events beyond their control. At the same time, the responsibility of perpetrators is diminished when, for example, 
social interaction is framed as an issue with the mind of the victim ${ }^{1}$. In this article, the authors focus on the ways in which victims are blamed or held responsible for their mistreatment, as if they have done something wrong. Elizabeth Fast and Cathy Richardson have documented this type of violence against Métis people, who have been blamed for their perceived deficiences, such as having fragmented identities or not being "Native enough" (Fast, 2016; Fast, Drouin-Gagné, Bertrand, Bertrand, \& Allouche, 2017; Hancock, 2017; Richardson, 2004, 2017; Vowel, 2017). Because the Métis are so misunderstood (and misrepresented) in Canada, this population falls through many systemic cracks and are denied rights, reparations, and appropriate social services (Richardson, 2004). In this article, Cathy Richardson contributes her response-based analysis, generated with colleagues Allan Wade, Linda Coates, and Shelly Bonnah, to elucidate how representations of violence tend to blame and pathologize victims and excuse or eliminate perpetrators from the account. Elizabeth Fast draws from her research and experience working with Indigenous women and youth.

Rachel Flowers (2015) offered us another perspective on the violence against Indigenous women. She noted that this type of gendered violence is linked to settler dispossession of Indigeous lands. Flowers believed that the concept of dispossession relates to the removal of bodies from the land as well as the disappearance of Indigenous people as free people. This kind of interpretation offers a challenge to the body politic of Canada and to the settler population. She wrote:

Over the last four years of organizing and speaking at the Memorial March for Missing and Murdered Indigenous Women in Victoria, I witnessed women and men come together in affirmation to share both their sorrow and love in remembrance of our sisters, and to demand that violence against Indigenous women come to an end. These demonstrations provide a counterdiscourse to the dominant narrative that Indigenous women and girls are "vulnerable" thereby placing the burden on us to not only protect ourselves by changing our "risky" behaviours, but also to find solutions to ongoing systemic violence and oppression (2015).

I believe that Flowers would concur that this issue relates not to being Indigenous women but to Canada's difficulty in naming and addressing white male supremacy. This discourse, although more accurate, is more provocative and volatile, and can actually bring more violence upon Indigenous women in the form of backlash. Yet, if allies from the settler community joined with Indigenous women and activists in moving the focus away from the victim-blaming rhetoric, we

\footnotetext{
${ }^{1}$ Richardson and Wade (2009) give examples of how diagnoses under the Diagnostic and Statistical Manual of Mental Disorders (DSM) are typically used to pathologize persons who have experienced violence. Victims of violence are often described as depressed, having boundary issues, anxious, hypervigilant, and so forth. Their responses are seldom described as social and understandable in context, but rather as signs of illness. Moreover, acts of resistance to violence are misconstrued as symptoms of pathology, as has been described by Todd and Wade (1994).
} 
International Journal of Child, Youth and Family Studies (2019) 10(1): 3-25

might have more success in changing perpetrator behaviour and addressing these forms of structural and interpersonal violence.

Despite increased attention to intervention and prevention after the Second World War, society has not been successful in stopping violence, including femicide, gay-bashing, and racially motivated crimes of hate. In Canada, Indigenous people comprise only $4.9 \%$ of the population (Statistics Canada, 2016) but are held accountable for a disproportionate number of crimes:Métis, Inuit, and First Nations men and women accounted for $27 \%$ of admissions to federal corrections services (Malakieh, 2018). For example, Indigenous youth accounted for just $8 \%$ of the youth population, but for fully $46 \%$ of youth admitted to youth correctional services in Canada (Statistics Canada, 2016). As well, Indigenous people experience a disproportionate amount of violence. In 2014, the rate of violent victimization among Indigenous people in Canada was more than double that of non-Indigenous people (163 incidents per 1,000 people versus 74 incidents per 1,000 people; Statistics Canada, 2016) and Indigenous women were 3 times as likely as non-Indigenous women to be a victim of violent crime (Statistics Canada, 2016). This article explores events that occur at the intersection of sexist and racist (e.g., anti-Indigenous) violence. The authors explore some of the implications of this violence in relation to the service sector with a view to problematizing and addressing victim-blaming. A contextual, response-based perspective is drawn upon to elucidate the interaction between violence and the responses to violence.

\section{Analysing Social Interaction}

We draw from research that shows that numerous discourses, including legal and psychological, hold victims responsible for their situation, suggesting that this misrepresentation is a main reason that violence in society remains ubiquitous and problematic.

As response-based practice is based on analyzing and understanding social interaction within context, we work with the idea of the inter-relatedness and connections of events and context. That is, what people do, within the context of their lives, can be studied with a lens that focuses on the importance of preserving dignity and increasing safety through action. Nora Bateson (2016) discusses this kind of "contextual integrity" and the role and limits of individual human agency within a background of context.

In symmathesy (interaction as a trans-systemic context for mutual learning), the idea of agency should be treated as a paradox that necessarily resides between the existence of the organism as a unique entity, and the simultaneous impossibility that this entity can be deontextualized or in any way uninfluenced by its contextual interactions. (p. 174)

This means that all action and interaction take place within context. To highlight this point in teaching, Richardson often poses the following questions: "Where you live, who is the most likely to be blamed for a crime they did not commit?" and, "Who is most likely to get away with a crime 
International Journal of Child, Youth and Family Studies (2019) 10(1): 3-25

they did commit?" Such questions highlight the power dynamics at play and what groups of people are most privileged, and which most disadvantaged, in society and its system of justice.

The study of interaction can begin at any given point. Once we choose a starting point, we analyze "who is doing what to whom". This means identifying the actions of the perpetrator, the co-responding actions of the victim and so on, back and forth. Simultaneously, we consider the anticipated or real social responses to both of these parties, in so far as the social responses inform and guide what each party may do. For example, if a woman is being raped by her husband, whether or not she decides to scream depends on what she knows about her neighbours and neighbourhood. If she thinks that her neighbours would likely help her, she may scream. If she understands that her screams would be ignored, she may choose another path, like going limp until it is over (Wade, personal communication, Duncan, BC, Canada, 2015). However, in accounts of violence in North America, the process of trying to understand victim resistance is largely omitted from public and legal processes. When victim resistance to a sexualized assault is taken up in court, it is usually presented in such a way as to accuse the victim of being a co-aggressor (Coates \& Wade, 2007).

\section{Analysing Discourse and Representation}

Coates and Wade (2007) proposed a model of "four-discursive-operations; namely, the concealing of violence, obfuscating of perpetrators' responsibility, concealing of victims' resistance, and blaming and pathologizing of victims" (p. 511). This "four operations of discourse" model demonstrates that when resistance to violence is concealed in the account of "who is doing what to whom", the three other functions are simultaneously performed. Specifically, when resistance is hidden, the violence and the level of brutality and deliberateness are also invisibilized. Often the perpetrator is removed entirely from the account and the victim is held responsible because they are the only party present in the description. One example can be found in former Prime Minister Stephen Harper's apology to residential school survivors (see https://www.aadncaandc.gc.ca/eng/1100100015644/1100100015649). He omitted any reference to the detailed strategies of colonial violence enacted by the state, as well as the role of mining and land companies in taking land from Indigenous people. Indigenous resistance, such as parents trying to hide their children from authorities, and avoid imprisonment and financial sanctions, was not mentioned; it would have pointed directly to the violence of the state. So, when the actions of the perpetrator (i.e., Canada, and specifically the members of the upper-middle-class Protestant elite who formed the government) are minimized and hidden, it becomes politically acceptable, and convenient, to refer to the "resilience" of the victims because, unlike resistance, resilience does not offer a challenge to the status quo nor shed light on the actions of the perpetrator. Violence was also hidden when particular strategies for government land theft were not mentioned in Prime Ministers Harper's apology. This would make any Indigenous movements such as "Idle No More", "Standing Rock", and the earlier Mohawk resistance ("Oka crisis") of 1990, seem disparate, and disconnected from the particular violence of the government. 
International Journal of Child, Youth and Family Studies (2019) 10(1): 3-25

When much of the discourse is focused on Indigenous mental illness (Flowers, 2015; Richardson \& Wade, 2009), the perpetrator and perpetrator's actions become obscured or invisibilized. Individualizing, pathological theories are applied to the victims, and to the state of their brains (e.g., neuropsychological versions of trauma theory, American Psychological Association presentations of mental illness, metaphorical descriptions such as "the Wounded Warrior" or "the soul wound"; Duran \& Duran, 1995). The problem of colonialism has then been transferred into an epidemic of Indigenous mental illness. Government resources can then, minimally, be put into mental health services rather than returning stolen land, returning profits from mineral and gas exploitation, and reuniting families.

\section{Highlighting Victim Responses and Resistance}

One reason to highlight victim responses and resistance is that it highlights victim capacity and depathologizes and recollectivizes behaviour. When the actions of the perpetrator are made clear, the level of violence and oppression also becomes clear, as well as the particular strategies used to discredit the victim(s). Attention to so-called lateral violence (violence within a group) is one of the successful strategies used by those in power to discredit the ability of Indigenous people to live harmoniously in their communities without paternalistic intervention.

Revealing victim resistance offers a counter-narrative to: (a) resist the construction of the victim as an unworthy, passive object who didn't do enough to stop the violence; (b) contest the ideas that women choose violent men, that Indigenous people like to be colonized, and that people of colour are not disturbed by racism because they are internally oppressed and have low selfesteem; and (c) minimize the use of trauma-based formulations (e.g., fight, flight, and freeze) that tell us that victims cannot act when in dangerous situations because the amygdala "hijacks" and "shuts down" the neocortex ${ }^{2}$, which is normally responsible for prioritizing people's actions and the meanings they make of them.

Eliciting resistance provides an antidote to victim-blaming because the victim is seen as an active agent, not a passive object, as one often finds in the literature on harmed, oppressed, and traumatized people (Bunce, Larsen, \& Peterson, 1995; van der Kolk, 2015). Throughout this article, we will provide a number of concrete examples of these linguistic functions as well as examples of other forms of victim-blaming.

\section{Blaming the Victim}

Blaming the victims, or targets, of violence contributes to their aggravated, extended, and unnecessary suffering. It is of crucial importance for recovery that victims receive positive social responses from family, friends, and professionals after they disclose violence, especially since

\footnotetext{
${ }^{2}$ Of course, this is not true or there would be no firefighters, heroes, or mothers who rescue their children. It is mainly when events are decontextualized that responses are not seen as ways of maximizing safety and dignity. "Playing dead" is not the same as freezing. In terms of accuracy, metaphors cannot be given the same weight as analysing interactions in context.
} 
International Journal of Child, Youth and Family Studies (2019) 10(1): 3-25

victims are often lacking in power and resources. However, the literature shows that very often, at least half the time, victims receive some of the blame (Andrews \& Brewin, 1990; Andrews, Brewin, \& Rose, 2003; Goffman, 1963; Richardson \& Wade, 2009). Blaming victims adds to the shame and humiliation that they already feel. Being a victim is so stigmatizing in our society that having been harmed by another is often seen as a stain on one's character - as if one has a "victim personality", or is weak or unclean. We will also demonstrate in this paper that sometimes being Indigenous is enough to make one be seen as guilty, because particular interactions take place in the context of interpersonal and systemic racism involving police, medical systems, child protection, and so on.

Violence involves one person acting against the will and well-being of another without consent (Wade, personal communication, Duncan, BC, Canada, 2015). It is not a mutual act. In response-based practice, the term "victim" is descriptive of an event rather than an identity. However, being a victim is seen so negatively in North America that many people decide never to talk about what has been done to them (Goffman, 1963; Patrick, 2018; Richardson \& Wade, 2008). If people do tell others about their experiences, they are commonly accused of "having a victim personality". Within the social sciences there is a field of study known as "victimology" but there is no parallel field called "perpetratorology". Criminology is a general field that does not relate specifically to studying perpetration. Indeed, one is legally a criminal only if sentenced; most perpetrators of violence are not.

\section{Mutualization and the Responsibilization of Victims}

When victims are Indigenous mothers, they are cast as having deserved the violence, and sometimes are actually seen as co-perpetrators. Coates \& Wade (2007) have demonstrated ways in which violence is often mutualized in its representations and the victims are seen as coresponsible. Conjugal violence researchers such as Lapierre $(2007,2008)$ and Bancroft \& Silverman (2002) found that mother-blaming was used by male perpetrators as either a pretext (e.g., bad mothering, bad housekeeping) or that mothers were treated more like co-perpetrators than victims after the fact. This, for example, is what is implied in the naming of the Truth and Reconciliation Commission (2015) of $\mathrm{Canada}^{3}$ - that the violence and the responsibility are mutualized. Reconciliation, from the Latin conciliare [to unite], is about restoring to wholeness that which was once whole and then was broken. Putting the onus of reconciliation on Indigneous people implies that Indigenous people have something they need to do to repair the relationship broken by white genocide.

In victim-blaming, there is sometimes an implication that the victims did something to bring the violence on themselves, such as not having boundaries, assertiveness skills, self-esteem, or a knowledge of self-defence. Allan Wade writes that this form of victim-blaming is like saying,

\footnotetext{
${ }^{3}$ The Truth and Reconciliation Commission was a national process in Canada designed to elicit stories from the survivors of residential schools and to document the violence and hardship experienced by the Indigenous children forced to attend these institutions. http://www.trc.ca/websites/trcinstitution/index.php?p=905
} 
International Journal of Child, Youth and Family Studies (2019) 10(1): 3-25

"If you weren't so Aboriginal, I wouldn't be so racist ... if you weren't so disabled, I wouldn't make fun of you ... if you weren't so annoying, I wouldn't beat you up." (Wade, personal communication, Duncan, BC, Canada, 2015). For women, the same logic states: if you want equality with men, you should have been born a man. For the Métis, victim-blaming involves condemning them for being mixed-race and not something "whole" (Fast et al., 2017; Richardson, 2004).

In a presentation at the Qualitative Research Conference in Champaign, Illinois (Fast, Boldo, Clark, Richardson, \& Smith, 2018), Elizabeth Fast cited a Métis participant who stated, "The word Métis in Quebec, this word doesn't exist: not in the family, not in the culture, not in the law, not in politics, not in the government." (Personal communication, Champaign, Illinois, 2018). Cathy Mattes, who also writes about the Métis experience, wrote:

I believe that for many Métis the experiences of being recognized and recognizing, being and becoming is internalized, and effects how we view ourselves. I would argue that it is embedded in the struggles of our relations, ourselves, government legislation, and being of mixed ancestry. It also comes from the general lack of acknowledgement about Métis people, our experiences, and our contributions. We are whole - a whole nation, whole families, whole individuals, yet sometimes, it seems that we are treated, or recognized as only being half. (Mattes, 2003, p. 6)

For women living in a context of inequality, not doing what partners, fathers, or bosses tell them to do is seen as an invitation for reprimand, criticism, or attack. When power relations are imbalanced to the advantage of the perpetrator, a refusal to comply does not tend to open space for mutual discussion, exploration, and solution-finding; instead, the result is often the resistance of the victim. Sharene Razack (2000) used a pioneer metaphor to describe the violence done to Indigenous woman Pamela George ${ }^{4}$ before and during her murder by two young white men, aged 19 and 20. George, a mother of two children, was from the Sakimay First Nation. Razack stated that the identities of the victim and the perpetrators were used in an analysis to minimize the violence of the young men and to transfer partial responsibility to the woman. George, because she was an Indigenous woman in a certain area of town, was characterized as belonging to a "zone of degeneracy", and the accused were seen as foreign to this space and therefore less culpable. The judge created a metaphor in which the boys enacted a "rite of passage", entering this dodgy space in order to come out as men. Other mutualizing constructs were used to blame Pamela George. For the perpetrators, hurting a woman, presumably while having an orgasm, was part of their "coming of age", marking the domination of white settler men over a First Nations woman.

According to Angus (1997), the court learned that Steven Kummerfield (20) and Alexander Ternowetsky (19) got drunk that night and decided to "look for a prostitute". They picked up

\footnotetext{
${ }^{4}$ Here, we honour the memory of Pamela George and send condolences to her family, friends and all the people who love and miss her.
} 
International Journal of Child, Youth and Family Studies (2019) 10(1): 3-25

Pamela George and took her to a gravel road near the airport, where they isolated her. Termowetsky had been hiding in the trunk. Kummerfield let him out. While George tried to escape, it was reported that they caught her and returned her to the car where they had "oral sex" and then "they proceeded to beat her" (p. 5). By this time, George had been screaming and trying to escape from these two men who eventually beat her to death. Another young male witness said he talked to Kummerfield, asking him what he did the night before. Kummerfield had told him: "Not much. We drove around, got drunk and killed this chick." (p. 5). Under cross examination, the witness amended his statement, now giving Kummerfield's words as, “' I think we killed her.' He also testified that Kummerfield told him they threatened to kill Pamela George if she refused to have sex ${ }^{5}$ with them." (p. 5).

The young men were charged with first degree murder and left the court convicted only of manslaughter. Mutualizing language and the fact that she was an Indigenous woman moving in an "unsafe" area of town made her, according to the Court, partially to blame for her fate.

\section{Response-Based Contextual Analysis}

Figure 1 illustrates the analytical process of response-based analysis and interviewing. We begin by taking into consideration the context, which we call social material conditions. This can include the particular historical background, such as colonization, as well as the current degree of social inequality. We often pose the question when teaching, "Where you live, who is most likely to be accused of a crime they did not commit; and who is most likely to be excused for a crime they did commit, an act that leads to perpetrator impunity?" The fact that the number of convictions for sexualized assault in Canada is only $1 \%$ of the number of people who have stated that they have been victims of such an assault (Johnson, 2012; Reynolds, 2014) is one indicator of the impunity found in what some refer to as rape culture (Reynolds, 2014) and others as a culture of impunity (Patten, 2008).

When women are trying to participate freely and fully in society, they seek to work, to engage politically, to be equal, to have full access to public spaces, and to dress how they want; however, asserting one's autonomy can be seen as an affront to those who want to protect the status quo or patriarchal advantage. The silencing by U.S. President Donald Trump of women speaking out is one prominent recent example of male oppression, and having lawyers and allies to help silence women is an example of a social response to a woman victim or a woman who challenges male power (Neumeister \& Hays, 2018). The context behind the \#MeToo disclosures demonstrates that women are in shock and disbelief when a man they trusted violates them and leaves them with the choice of staying quiet or speaking out and becoming unemployed. However, this kind of exploitation is going on all the time: the violation of single mothers by landlords, the sexual

\footnotetext{
${ }^{5}$ In this article, sex is defined as a mutual and consensual act between adults. In a climate of violence and coercion, such an interaction constitutes violence, not sex.
} 
innuendos of shopkeepers or restaurant owners to women employees who need the job, and so on. Mothers, in particular, are more vulnerable because they need the job to support their children.

\section{Response-Based Contextual Analysis}

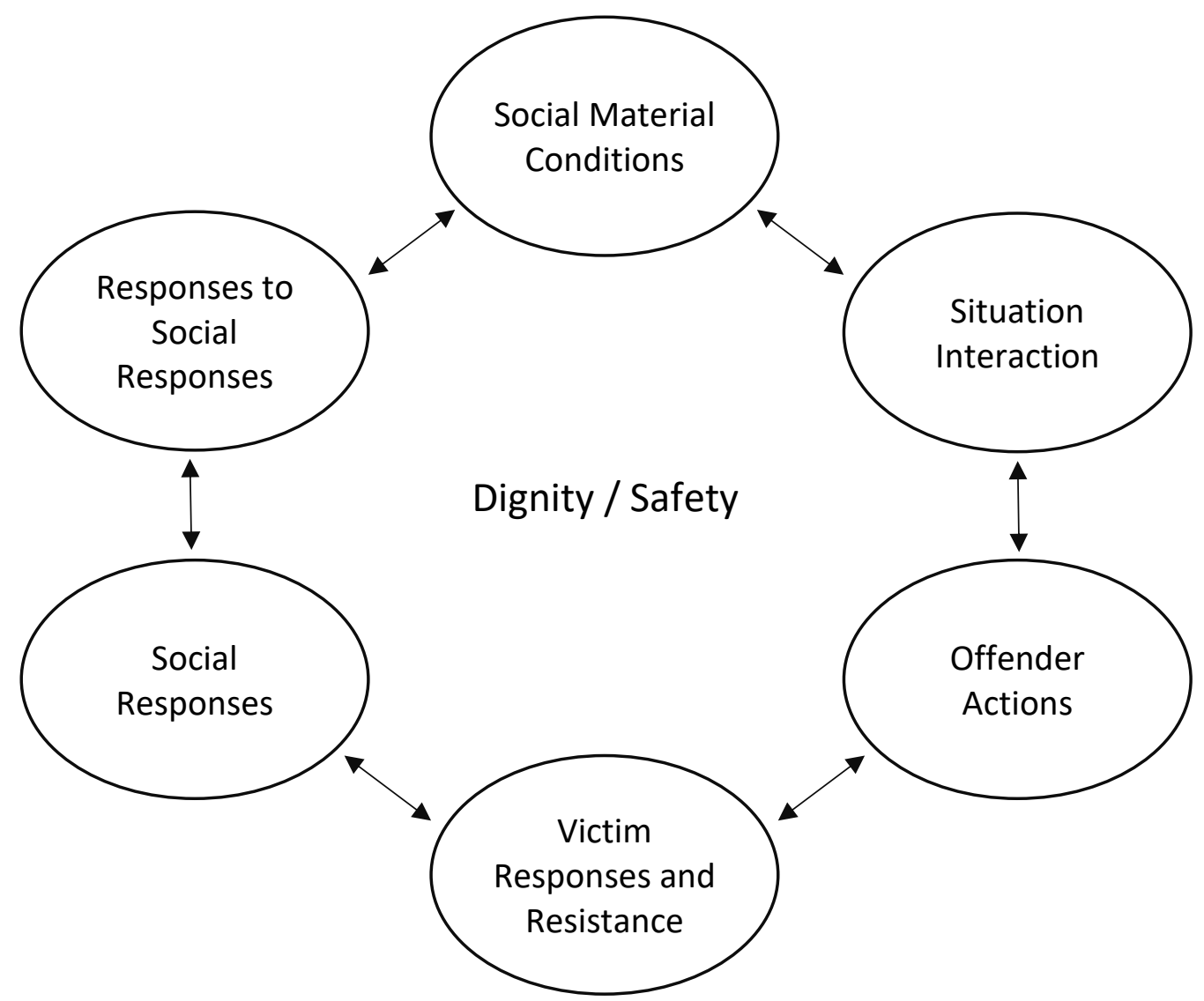

Figure 1. The analytical process of response-based analysis and interviewing (adapted from Bonnah, Coates, Richardson, \& Wade, 2014, as presented by Wade, 2015).

The Government of Canada (2017) reported that $60 \%$ of respondents to an online survey (approximately 83\% of whom identified as female) stated that they had experienced non-sexual harassment at work; $30 \%$ had experienced sexual harrassment, $21 \%$ had experienced non-sexual violence, and $3 \%$ had experienced sexual violence.

As well, universities haven't been safe places for women as either students or employees (Fox, 2018). Recent reports show that violence, harassment, and sexual violence are widespread on university campuses and that we have not yet found a meaningful way of addressing the problem (Xing, 2017). In relation to violence and harassment for staff, faculty, and students on Canadian university campuses, Chiose (2017) reported in The Globe and Mail newspaper that:

Canadian universities try to resolve most complaints of harassment or discrimination made by staff, faculty and students informally, numbers collected 
International Journal of Child, Youth and Family Studies (2019) 10(1): 3-25

from more than 20 institutions and analyzed by The Globe and Mail reveal. The data show that less than 10 per cent of complaints are resolved through a formal investigation, with some institutions turning to a formal process in less than 1 per cent of cases.

The reality is similar for charges of sexual assault, which researcher Holly Johnson referred to as the attrition of sexual assault charges; she noted that while 460,000 women self-reported a sexual assault in 2004, only 1,519 males were convicted of a sexual assault during 2006 (Desson, 2014). Johnson's (2012) research showed that of the assaults that are reported, most do not make it to the charging or sentencing stage of the court process. The fact that there are so few convictions means that life becomes less safe for these women, who are then sometimes accused of making false allegations. In 2016, Cathy Richardson documented the court case of sexual assault of a minor in the Yukon Territory in which a young woman experienced harrassment by family members (her family and the family of the alleged perpetrator) while waiting over two years for her case to go through the courts.

When a culture of impunity for perpetrators is created, they can get away with their violations and the reputation of the victims gets called into question. One researcher stated that "it has become ‘open season' on Indigenous women” (Wade, 2015).

Another issue is that many people are conflict-avoidant and find these kinds of situations very tense. In a culture where being polite is valued, individuals may have difficulty naming and addressing the actions of a violent perpetrator in the context of family life. In many cases, therefore, allegations are swept under the rug. Linda Coates (1997) has demonstrated that this effect can be worse in the court sytem because the woman (i.e., victim of sexualized assault) faces a defence lawyer attacking her character and even bringing up her sexual history in jurisdictions where that is still permitted. This phenomenon of extracting sexual history from women in rape trials is documented by McGlynn (2017) and Thomasson (2018), who discussed some of the legal, ethical, and social justice issues related to this practice, which some would see as sexist.

\section{The Mechanics of Victim-Blaming}

Violence, which we know is unilateral, is described as something mutual ("it takes two to tango"). An assault may be referred to as a conflict or a fight, implying that two parties share responsibility for the violent events. We might assume that two parties contribute to a "loving relationship", and then apply the same logic to spousal assault or a violent relationship. The issue is that "loving" is typically a mutual act while violence is unidirectional6 (Coates \& Wade, 2007).

\footnotetext{
${ }^{6}$ In the case where both parties "put on gloves and get into the ring together", we could call this a fight and regard it as consensual, unlike violence. To be helpful and accurate in the field, it is crucial to understand the difference between violence and self-defence, and between violence and conflict.
} 
International Journal of Child, Youth and Family Studies (2019) 10(1): 3-25

\section{The Difference between Violence and Self-Defence}

If we believe that people resist violence and mistreatment, as response-based thinking invites us to believe, then we probably understand the difference between violence and selfdefence. This distinction is crucial in the violence prevention field. However, in jurisdictions where there is dual charging (i.e., both parties in a domestic dispute are charged), many women who have tried to defend themselves have been sentenced as secondary aggressors (Johnson, 2012). And, in some situations where the perpetrator is particularly convincing, the victim can even be seen as the primary aggressor ${ }^{7}$ (Elizabeth, Gavey, \& Tolmie, 2012).

Victim-blaming is also achieved through the misrepresentation of violence as sex. Many would probably say they can distinguish between sex and violence. Consensual sex can be a loving, mutual practice between two consenting adults ${ }^{8}$. Canada's criminal code articulates the impossibility of an adult having consensual sex with a child (Coates, Bavelas, \& Gibson, 1994): consent is unacceptable as a legal defence (Criminal Code, 1985). Due to the age differential and the "in loco parentis", or caretaker, responsibility of an adult, acts that are often referred to as sexual instead should be seen as violence. These include sexual assault, sexual touching, sexual interference, kissing, fondling, sexual aggressivity, and so forth (Coates et al., 1994). Dr. Linda Coates has found through her research on violence discourses in the courtroom that whenever violence against children is referred to as "sexual", responsibility is mutualized and sentences are lower or sometimes nonexistent; a few years back, a Canadian judge was reprimanded for responsibilizing a child, referring to the young child as "sexually aggressive" (Coates, personal communication, Australia, 2017).

\section{The Importance of Accurate Language}

Wade (personal communication, Duncan, BC, Canada, 2015) illustrated the inappropriateness of the confusion between sex and violence by saying:

If someone comes up to you and, with force and slobber, assaults you with their mouth, on your face, we could call that forced oral contact. However, that typically gets called "a kiss". Harassment at school or work is typically referred to as a personality conflict, rape is referred to as sex, invasion is typically referred to as war, genocide in Canada is referred to as "the Indian problem".

Often perpetrators are excused for the harm they cause others because they themselves were hurt as children. However, this kind of rationalization of criminal behaviour is less generous

\footnotetext{
${ }^{7}$ A mother who is trying to protect her children from the violence of the father can be seen as "alienating" the children from the father. Parental alienation is punished in courts, in child protection systems, and in psychological assessments. See the work of Simon Lapierre and Isabelle Côté (2016) on mother-blaming and the inaccurate assumptions behind parental alienation.

${ }^{8}$ Although as Esther Perel points out in a FIAF talk, not all consensual sex is wanted. https://www.youtube.com/watch?v=TO97dxYoqXo
} 
International Journal of Child, Youth and Family Studies (2019) 10(1): 3-25

with Black and Indigenous men and more prominent when the perpetrators are Caucasian with European descent (Razack, 2000). Perpetrators are sometimes pathologized through the use of deficit psychological labels and conditions, even if some of these diagnoses do not have violence as part of their symptomatology (Wade, personal communication, Duncan, BC., 2015). In our experience, psychological reports typically refer to attachment disorders in adults as well as borderline, narcissistic, or oppositional personality disorders. Sometimes, attention deficit hyperactivity disorder is listed as a causal factor in relation to violence, even though this connection may be spurious.

\section{Problematic Recasting of Problems of Violence As Problems of Anger, Alcohol, and so on}

Very often, people who use violence are said to have anger or alcohol problems. Why would the problem of violence sometimes be recast as a problem with alcohol or a problem with anger? And, why is this problematic? There are individuals who drink alcohol, or get angry, who never hit or abuse anyone, just as there are sober people who use violence with calculation and cruelty. There are people who live with anger who do not assault others, but perhaps channel their anger into activism, social justice, or social change, just as there are people who are calm and collected and who use violence and control for their own purposes. Perhaps one reason why we haven't been able to address violence in our society effectively is that we make inaccurate assumptions and send people to the wrong kinds of programs. Logically, if someone has a problem with violence we should send them to a violence cessation program.

\section{The Unworthy Victim}

We blame victims by referring to them as passive, as people who do not do things to help themselves. When we do give victims agency, it is usually to say that they have used their agency in ways that cause harm. We say that they actively choose bad partners, that they are trying to relive the abuse of their childhood in their adult relationships, and that, because they don't have boundaries, they choose men who are going to hurt their children. Media researcher Yasmin Jiwani (2011) documented this misogynistic representation:

In this climate of seemingly diverse media representations, women who are victims of violence are often accused of playing the victim card. The idea that these women are able to choose victimhood over resilience and survival is a lie embedded in the neo-liberal ethic of consumer society and obscures the structural conditions that mediate and constrain the latitude of choice. (paragraph 2)

This false representation of women victims raises questions about who benefits from these disparaging representations. For women victims, these practices cause harm and, as negative social responses in the aftermath of violence, they have the power to inflict what is often referred to as secondary traumatization. Jiwani goes on to spell out how certain women are more likely to be blamed than others and that these representations tend to align with the degree of power that 
International Journal of Child, Youth and Family Studies (2019) 10(1): 3-25

particular woman already possesses in the social hierarchy, with women of colour and Indigenous women being more likely to be negatively represented.

So, in the face of these negative accounts, how do we then treat mothers who are seen as guilty, passive, or unprotective with regard to their children in the context of violence, even when both women and children are the targets? Social science textbooks tend to make sweeping generalizations about people who have been harmed or oppressed, talking about how such people are all affected by violence (and now also by trauma). While there may be some helpful interventions associated with trauma care, we must analyze the social consequences of reducing male violence to issues in the brains of individual victims. In child welfare interventions, as part of what is termed a parent's "failure to protect", mothers who have been victims of male partner violence are told that they cannot parent due to their trauma and psychological issues. We give their children to someone else to raise, sometimes to the perpetrator. Child protection workers recognize this victim-blaming behaviour in their co-workers as well. One worker spoke about how Indigenous women are all lumped together and labelled as deficient due to the generalized history in Canada, regardless of tribal affiliation, class, or access to supports and services. The mass stigmatization of residential school survivors, based on an exaggeration and overuse of the theory of intergenerational effects, can prevent child protection workers from accurately analyzing cases involving Indigenous mothers (Wade, 2015).

One aspect of social unfairness is the unequal supports available to birth parents versus foster parents in child welfare settings. This practice undermines Indigenous mothers who want to keep their children but are judged negatively due to poverty or to being the victims of spousal abuse. In British Columbia, foster parents would formerly receive more funding for Indigenous children than for other children because all Indigenous children were considered to have "special needs" (Becky Madina, B.C. Ministry of Child and Family Development, personal communication, 2005). Jiwani (2014) showed that the nature of the portrayals of rape victims and rape perpetrators is based on their race, with members of the dominant culture being portrayed more favourably. Further, these media portayals influence how the various parties are viewed in society, as well as in court settings.

According to the logic of the courts, if a woman leaves home and goes to a shelter while the man she has been living with stays in the house, she is seen as homeless and the man is seen as the more stable parent. She is blamed for her situation, in spite of making good safety decisions for her and for her children. We need to turn to better examples of mother-care, like the Safe At Home program in Western Australia, where the male perpetrator is escorted from the home and placed in a shelter. In these cases, the victims are not seen as the guilty party (see http://www.womenscouncil.com.au/safe-at-home.html).

\section{Recommendations}

Child welfare reform with Indigenous families is something we have been advocating for many years now. We need to reverse the victim-blaming policies that fail to protect Indigneous 
International Journal of Child, Youth and Family Studies (2019) 10(1): 3-25

families and that separate mothers from their children. We can reverse the four operations of discourse to support victims and hold perpetrators accountable.

If we want victims to speak out and come forward to press charges, then we need to create a culture in which it is safe to do so. Fears that this will lead to many false claims are unfounded: research shows that the proportion of false claims of sexualized abuse is quite low (Institut National de Santé Publique du Québec) ${ }^{9}$. We need to understand that being a vicitm of violence is not the fault of the victim and has nothing to do with one's efficacy as a parent. In cases where a caregiving parent is temporarily unable to parent, relatives can typically be found to take care of the children; the large canon of Indigenous child welfare literature (Carrière \& Richardson, 2016; Fast, 2016; Richardson \& Carrière, 2012; Richardson \& Nelson, 2007) advocates for kinship care and family support.

We must stop blaming Indigenous mothers for the violence they were subjected to in residential school, in foster care, and in their family of origin. Despite recommendations against it, many child protection risk assessments still pose "double-bind" questions asking about the history of violence. A question such as "Did your parents harm you as a child?" is designed to seek a history to which a deterministic logic can be applied: a person who has been harmed will thoughtlessly reproduce the violence and not make different choices about how to act. People who answer "Yes" have a greater chance of being put into a high-risk category and losing custody of their children (Ministry of Youth and Family Services, 2016). Interviews conducted for Carrière and Richardson's 2017 book Calling our Families Home indicated that, although some child welfare practices are becoming more collaborative, deterministic tools for assessing risk are sometimes still applied. We know this kind of thinking is false, that there are other factors to consider, such as the quality of the social responses received systemically and from family and friends. Many people who experienced violence never went on on to use violence against others and, in fact, made commitments never to reproduce what they had experienced as children. But we do know that most of the violence that is committed against Indigenous people is perpetrated by people who were harmed and violated, many in the care of the state. And, more generally, sexualized violence against women and children in particular contexts (e.g., colonization, war, political aggression) is understood as a tactic of domination:

The unacceptable reality today is that it is still largely cost-free to rape a woman, child or man in many situations of conflict around the world, and sexual violence continues to be employed as a tactic of war, terrorism, torture and repression. It is used precisely because

\footnotetext{
9 "On the basis of a representative sample of 7672 cases of abuse investigated by child protection authorities in Canada, Trocmé and Bala (2005) noted that only $4 \%$ of the $35 \%$ of unsubstantiated cases were deemed to be the product of intentionally fabricated false allegations. The rate was slightly higher in cases of sexual abuse $(6 \%)$ compared with cases of physical abuse (4\%), neglect (4\%), and emotional maltreatment (2\%). However, none of the false allegations of sexual abuse had come from the children themselves." (Institut National de Santé Publique du Québec, n.d., False allegations of child sexual abuse, section 1, paragraph 2)
} 
International Journal of Child, Youth and Family Studies (2019) 10(1): 3-25

it is such an effective and devastating weapon, destroying not only individuals, but tearing apart families, and fracturing communities. (Patten, 2008)

This quote describes the kind of violence inflicted on Indigenous boys and girls in Canadian residential schools: it is a form of violence used to silence people and keep them down.

One of the things that we can continue to do is to speak out publicly about the injustices and misrepresentations of violence that we see as we do our work. However, in order to remain alive in the work, it is important to celebrate small victories and to bring joy and kindness into the work (Richardson \& Reynolds, 2012). Giving-back practices are important. This means making sure that colleagues and co-resistors know when their actions have made a difference, promoted systems change, and made life better, even for one person. 
International Journal of Child, Youth and Family Studies (2019) 10(1): 3-25

\section{References}

Amnesty International. (2004). Amnesty International Report on the Stolen Sisters: A human rights response to discrimination and violence against Indigenous women in Canada [AI Index: AMR 20/003/2004]. Ottawa, ON: Author. Retrieved from https://www.amnesty.ca/sites/amnesty/files/amr200032004enstolensisters.pdf

Andrews, B. \& Brewin, C. R. (1990). Attributions of blame for marital violence: A study of antecedents and consequences. Journal of Marriage and Family Therapy, 52, 757-767. doi: $10.2307 / 352940$

Andrews, B., Brewin, C. R., \& Rose, S. (2003). Gender, social support and PTSD in victims of violent crime. Journal of Traumatic Studies and the Homeless, 19(1), 421-427. doi:10.1023/A:1024478305142

Angus, A. (1997). Saskatchewan justice on trial: The Pamela George case. Saskatchewan Indian, 27(1), 5. Retrieved from http://www.sicc.sk.ca/archive/saskindian/a97apr05.htm

Bancroft, L., \& Silverman, J. (2002). The batterer as parent: Addressing the impact of domestic violence on family dynamics. London, UK: Sage.

Bunce, S. C., Larsen, R. J., \& Peterson, C. (1995). Life after trauma: Personality and daily life experiences of traumatized people. Journal of Personality, 63(2), 165-188.

Carrière, J. \& Richardson, C. (2016). Calling our families home: Métis peoples' experiences of child welfare. Vernon, BC: JCharlton.

Chiose, S. (2017, November 12). Justice on campus. The Globe and Mail. Retrieved from https://www.theglobeandmail.com/news/national/education/canadian-universities-underpressure-to-formalize-harassment-assaultpolicies/article29499302/

Coates, L. (1997). Causal attributions in sexual assault trial judgements. Journal of Language and Social Psychology, 16(3), 278-296. doi:10.1177/0261927X970163002

Coates, L., Bavelas, J. B., \& Gibson, J. (1994). Anomalous language in sexual assault trial judgements. Discourse \& Society, 5(2), 189-206. doi:10.1177/0957926594005002003

Coates, L., \& Wade, A. (2007). Language and violence: Analysis of four discursive operations. Journal of Family Violence, 22(7), 511-522. doi:10.1007/s10896-007-9082-2

Criminal Code, R.S.C. 1985, c. C-46, s.150.1(1). 
International Journal of Child, Youth and Family Studies (2019) 10(1): 3-25

Desson, C. (2014, December 5). What happens when someone is sexually assaulted: Statistics Canada says few convictions. The Star. Retrieved from Retrieved from https://www.thestar.com/news/canada/2014/12/05/conviction_rate_for_sexual_assault_very _very_low_researcher.html

Duran, E., \& Duran, B. (1995). Native American post colonial psychology. Albany, NY: State University of New York Press.

Elizabeth, V., Gavey, N., \& Tolmie, J. (2012). “...He's just swapped his fists for the system”: The governance of gender through custody law. Gender \& Society, 26(2), 239-260. doi: $10.1177 / 0891243211434765$

Fast, E. (2016). Hello ... We're Métis!! Promoting Métis visibility in the Quebec child welfare system. In J. Carrière \& C. Richardson (Eds.), Bringing our families home (pp. 137-152). Vernon, BC: JCharlton.

Fast, E., Boldo, V., Clark, M., Richardson, C., \& Smith, M. (2018, May). Coming together around the fire: Métis women, kinship and expanding the circle. Presented at the Fourteenth Congress of Qualitative Inquiry, Champaign-Urbana, IL.

Fast, E., Drouin-Gagné, M.-E., Bertrand, N., Bertrand S., \& Allouche, Z. (2017). Incorporating diverse understandings of Indigenous identity: Towards a broader definition of cultural safety for urban Indigenous youth. AlterNative: An International Journal of Indigenous Peoples, 13(3), 152-160. doi:10.1177/1177180117714158

Flowers, R. (2015). Refusal to forgive: Indigenous women's love and rage. Decolonization: Indigeneity, Education \& Society, 4(2), 32-49.

Foucault, M. (1991). Discipline and punish: The birth of a prison. London, UK: Penguin.

Fox, M. (2018, June). Sexual harassment at universities must stop, report says. The secondworse place to be a woman? Academia. NBC News. Retrieved from https://www.nbcnews.com/health/health-news/sexual-harassment-universities-must-stopreport-says-n882396

Garkawe, S. (1994). The role of the victim during criminal court proceedings. University of New South Wales Law Journal, 17(2), 595-616.

Goffman, E. (1963). Stigma. London, UK: Penguin.

Gramsci, A. (1971). Selections from the prison notebooks of Antonio Gramsci. New York, NY: International. 
International Journal of Child, Youth and Family Studies (2019) 10(1): 3-25

Government of Canada. (2017). Harrassment and sexual violence in the workplace. Public consultations: What we heard. Ottawa, ON: Employment and Social Development Canada. Retrieved from https://www.canada.ca/en/employment-social-development/services/healthsafety/reports/workplace-harassment-sexual-violence.html

Hancock, R. L. A. (2017). "We know who our relatives are”: Métis identities in historical, political, and legal contexts. In J. Carrière \& C. Richardson (Eds.), Calling our families home: Métis peoples' experiences with child welfare (pp. 9-30). Vernon, BC: JCharlton.

Institut National de Santé Publique du Québec. (n.d.). Media kit on sexual assault: False allegations of child sexual abuse. Retrieved from https://www.inspq.qc.ca/en/sexualassault/fact-sheets/false-allegations-child-sexual-abuse

Jiwani, Y. (2011). Hierarchies of worthiness: Women and victimhood in the media. Briarpatch, May-June. https://briarpatchmagazine.com/articles/view/hierarchies-of-worthiness

Jiwani, Y. (2014). Rape and race in the Canadian Press: Reproducing the moral order. Arts and Social Sciences Journal, S:1, 1-9. doi:10.4172/2151-6200.S1-009

Johnson, H. (2012). Limits of a criminal justice response: Trends in police and court processing of sexual assault. In E. Sheehy (Ed.), Sexual assault in Canada: Law, legal practice and women's activism (pp. 613-634). Ottawa, ON: University of Ottawa Press.

Lapierre, S. (2007). Taking the blame? Women's experience of mothering in the context of domestic violence [Unpublished doctoral dissertation]. University of Warwick, Coventry, UK.

Lapierre, S. (2008). Taking the blame? Women's experiences of mothering in the context of domestic violence. Safe: The Domestic Abuse Quarterly, 25, 4-7.

Lapierre, S., \& Côté, I. (2016). Abused women and the threat of parental alienation: Shelter workers' perspectives. Children and Youth Services Review, 65, 120-126.

Malakieh, J. (2018). Adult and youth correctional statistics in Canada, 2016/2017 [85-002X201800154972]. Juristat. Retrieved from https://www150.statcan.gc.ca/n1/pub/85-002x/2018001/article/54972-eng.htm

Mattes, C. (2003). Cowboys and Indians (and Métis?) by David Garneau: Response by Cathy Mattes. PaperWait, 6, 6-9.

McGlynn, C. (2017). Rape trials and sexual history evidence: Reforming the law on 3rd party evidence. The Journal of Criminal Law, 81(5), 367-392. doi:10.1177/0022018317728824 
International Journal of Child, Youth and Family Studies (2019) 10(1): 3-25

Ministry of Youth and Family Services. (2016). Ontario child protection tools manual (2016): A companion to the Ontario Child Protection Standards. Toronto, ON: Author. Retrieved from http://www.children.gov.on.ca/htdocs/English/documents/childrensaid/ChildProtection-Tools-Manual-2016.pdf

Neumeister, L., \& Hays, T. (2018, December 12). "Dirty deeds": Ex-Trump lawyer Cohen gets three years in prison. The Washington Post.

Patrick, W. (2018, April 9). How social stigma silences domestic violence victims: Why many domestic violence victims are reluctant to report [Blog]. Psychology Today. Retrieved from https://www.psychologytoday.com/ca/blog/why-bad-looks-good/201804/how-social$\underline{\text { stigma-silences-domestic-violence-victims }}$

Patten, P. (2008, October). Moving from a culture of impunity to a culture of deterrence: The use of sanctions in addressing sexual violence in conflict. Remarks given at the Arria meeting of the United Nations Security Council, ECOSOC Chamber, New York, NY. Retrieved from https://www.un.org/sexualviolenceinconflict/statement/remarks-by-srsg-svc-pramilapatten-at-the-arria-meeting-of-the-security-council-moving-from-a-culture-of-impunity-toa-culture-of-deterrence-the-use-of-sanctions-in-addressing-sexual-violenc/

Razack, S. (2000). Gendered racialized violence and spatialized justice: The murder of Pamela George. Canadian Journal of Law and Society, 15(2), 91-130. doi:10.1017/S0829320100006384

Reynolds, V. (2014). Resisting and transformating rape culture: An activist stance for therapeutic work with men who use violence. The No To Violence Journal, Spring, 29-49.

Richardson, C. (2004). Becoming Metis: The relationship between Metis stories and the sense of cultural self [Doctoral dissertation]. University of Victoria, Victoria, BC. Retrieved from https://dspace.library.uvic.ca/bitstream/handle/1828/655/richardson_2004.pdf;sequence=1

Richardson, C. (2009, May). Speaker on a panel entitled Nation state responses to violence against Indigenous women co-sponsored by The Indigenous Women's Network, Amnesty International, 7th Generation Fund, American Indian Law Alliance, Huairo Commission, GROOTS International, and GROOTS Canada at the Eighth Session of the United Nations Permanent Forum on Indigenous Issues, New York.

Richardson, C. (2017). Metis-astute social work: Shining the light on some helpful practices. Journal of Indigenous Social Development, 6(1), 82-89.

Richardson, C., \& Carrière, J. (2012). Following the lines of flight: Conducting delegation research in a Métis agency. Perspectives Magazine, 34(2). 
International Journal of Child, Youth and Family Studies (2019) 10(1): 3-25

Richardson, C., \& Nelson, B. (2007). A change of residence: From residential schools to foster homes as sites of Aboriginal cultural assimilation. First Peoples Child \& Family Review, $3(2), 75-83$.

Richardson, C., \& Reynolds, V. (2012). "Here we are, amazingly alive": Holding ourselves together with an ethic of social justice in community work. International Journal of Child, Youth and Family Studies, 3(1), 1-19. doi:10.18357/ijcyfs31201210471

Richardson, C., \& Wade, A. (2009). Taking resistance seriously: A response-based approach to social work in cases of violence against Indigenous women. In J. Carrière \& S. Strega (Eds.), Walking this path together: Anti-racist and anti-oppressive child welfare practice (pp. 193-216). Winnipeg, MB: Fernwood.

Rudenko, N. (2017). "The crisis of representation" in the social sciences in the middle of the 1980-1990s. Epistemology and Philosophy of Science, 51(1), 206-220. doi:10.5840/eps201751119

Shingler, B. (2016, November 14). 37 cases of alleged police abuse in Val-d'Or handed over to Crown: 'Stunning' number of complaints following Radio-Canada probe into allegations of abuse by officers. CBC News. Retrieved from https://www.cbc.ca/news/canada/montreal/val-dor-abuse-surete-du-quebec-montreal-police$\underline{1.3849786}$

Thomason, M. J. (2018). Previous sexual history evidence: A gloss on relevance and relationship evidence. International Journal of Evidence and Proof, 22(4), 342-362. doi:10.1177/1365712718793434

Todd, N., \& Wade, A. (1994). Domination, deficiency, and psychotherapy: Parallel objectifying practices. The Calgary Participator, 37-46.

Truth and Reconciliation Commission. (2015). Canada's residential schools: The Metis experience. The Final Report of The Truth and Reconciliation Commission of Canada (Vol. 3). Montreal, QC: McGill-Queens Press. Retrieved from http://www.myrobust.com/websites/trcinstitution/File/Reports/Volume_3_Metis_English_ $\underline{\text { Web.pdf }}$

Val-d'Or. (2016, November 15). La Presse. Retrieved from http://www.lapresse.ca/actualites/justice-et-faits-divers/201611/15/01-5041555-val-doraucune-accusation-contre-six-policiers-suspendus.php

Val-d'Or crisis. (2016, November 26). The Nation. Retrieved from http://www.nationnews.ca/val-dor-crisis-flames-anew-no-charges-local-sq-officers/ 
International Journal of Child, Youth and Family Studies (2019) 10(1): 3-25

Van der Kolk, B. (2015). The body keeps the score: Brain, mind, and body in the healing of trauma. New York, NY: Random House.

Vowel, C. (2017). Indigenous writes: A guide to First Nations, Métis \& Inuit issues in Canada. Winnipeg, MB: Portage \& Main Press.

Wade, A. (1997). Small acts of living: Everyday resistance to violence and other forms of oppression. Contemporary Family Thearpy, 19(1), 23-29. doi:10.1023/A:1026154215299

Wade, A. (2015, November). Telling it like it is. Keynote presentation for The Women's Council for Domestic and Family Violence Services (WA), Perth, Australia.

Whipps, H. (2008, March 30). How the council of Nicea changed the world. Livescience. Retrieved from www.livescience.com/2410-council-nicea-changed-world.html

Xing, L. (2017, September 12). Sexual assault policies at universities fail the people they're supposed to protect, students say. $C B C$ News Online. Retrieved from https://www.cbc.ca/news/canada/toronto/campus-sexual-assault-policies-in-ontario-don-tmeet-student-expectations-1.4281177 